\title{
Metais pesados em amostras biológicas de bovinos
}

\author{
Heavy metals in cattle biological samples
}

\section{Maria Verônica de Souza ${ }^{{ }^{*}}$ Matheus Werner de Souza Vianna' ${ }^{\mathrm{I}}$ Bruna Mota Zandim ${ }^{\mathrm{I}}$ Raphael Bragança Alves Fernandes ${ }^{\text {II }}$ Maurício Paulo Ferreira Fontes ${ }^{\text {II }}$}

\section{RESUMO}

O objetivo deste trabalho foi determinar a concentração de metais pesados no sangue ( $\mathrm{Pb}, \mathrm{Ni}$ e $\mathrm{Cd})$, soro (Cu e $\mathrm{Zn}$ ), pelo e leite ( $\mathrm{Pb}, \mathrm{Ni}, \mathrm{Cd}, \mathrm{Cu}$ e $\mathrm{Zn}$ ) de bovinos criados em área industrializada (com siderúrgicas) e não-industrial do Estado de Minas Gerais, em amostras coletadas em duas épocas (inverno e verão), buscando avaliar a contaminação em animais em função do ambiente de exposição e da estação do ano. O local de criação dos animais afetou significativamente somente a concentração de $\mathrm{Cu}$ obtida nas amostras de soro, com maiores valores determinados no grupo de bovinos da região industrializada. A época de amostragem afetou a concentração dos metais $\mathrm{Cu}$ (soro), $\mathrm{Zn}$ (soro e leite), $\mathrm{Pb}$ (sangue) e Cd (sangue e pelo), com as determinações efetuadas no verão proporcionando maiores teores do que as executadas no inverno, à exceção do Cd avaliado no pelo. Interações significativas $(P<0,05)$ entre área de criação e época do ano foram verificadas para $\mathrm{Cu}$ (pelo e leite), $\mathrm{Zn}$ (pelo) e $\mathrm{Ni}$ (soro, pelo e leite). Os resultados obtidos indicam que a presença de siderúrgicas em determinada região não implica, necessariamente, incrementos nas concentrações de metais pesados em matrizes biológicas de bovinos. Pode haver influência da sazonalidade nas concentrações de metais pesados obtidas nessas matrizes, fato que deve ser considerado em programas de monitoramento ambiental.

Palavras-chave: contaminação de animais domésticos, poluição, ruminantes, bioindicadores, componentes biológicos.

\section{ABSTRACT}

The aim of this research was to determine the heavy metals concentration in blood $(\mathrm{Pb}, \mathrm{Ni}$ and $\mathrm{Cd})$, serum $(\mathrm{Cu}$ and $\mathrm{Zn})$, hair and milk ( $\mathrm{Pb}, \mathrm{Ni}, \mathrm{Cd}, \mathrm{Cu}$ and $\mathrm{Zn})$ of cattle raised in industrial (with steel mill) and non-industrial areas in Minas Gerais, Brazil. The samples were collected during summer and winter, aiming to verify animals contamination related to environment and year season. The environment significantly influenced the concentration of $\mathrm{Cu}$ obtained on serum samples, with higher values for cattle from the industrialized area. The sampling time affected the concentration of $\mathrm{Cu}$ (serum), $\mathrm{Zn}$ (serum and milk), Pb (blood) and Cd (blood and hair), with higher values for summer, except for Cd measured on hair. Meaningful interactions $(P<0.05)$ between environment and year season were identified for $\mathrm{Cu}$ (hair and milk), $\mathrm{Zn}$ (hair) and Ni (serum, hair and milk). The results obtained show that the presence of steel mills in a determined area does not mean, necessarily that higher concentration of heavy metals will be found in cattle biological matrices, fact that should be considered in environment monitoring programs.

Key words: domestic animals contamination, pollution, ruminants, bio-indicators, biological components.

\section{INTRODUÇÃO}

Os metais pesados estão presentes no planeta como constituintes naturais de solos e rochas, bem como em muitos produtos e utensílios que manuseamos. Várias são as fontes desses elementos que podem contaminar o solo, a água e as plantas e, por conseguinte, os animais (KUNO et al., 1999; SWARUP et al., 2005) e o próprio homem (SRIVASTAVA \& GUPTA, 1994; DUARTE \& PASQUAL, 2000), dentre as quais se destacam a deposição atmosférica, os resíduos agropecuários, os fertilizantes e os corretivos, os agroquímicos, os lodos de esgoto, a água de irrigação, os compostos de lixo urbano e os resíduos urbanos, industriais e de mineração.

'Departamento de Veterinária (DVT), Setor de Clínica, Universidade Federal de Viçosa (UFV), Campus Universitário, s/n, 36570000, Viçosa, MG, Brasil. E-mail: msouza@ufv.br. "Autor para correspondência.

"Departamento de Solos, UFV, Viçosa, MG, Brasil. 
Embora o tema relacionado à contaminação por metais pesados em vários animais seja largamente abordado pela literatura científica, em bovinos, esse estudo ainda é limitado. Além disso, também são frequentes os trabalhos que relacionam os efeitos desses elementos químicos sobre a saúde humana ou sobre algum compartimento ambiental específico, como é o caso do solo, dos sedimentos, da vegetação ou da água. Obviamente, quando esses compartimentos estão contaminados, existe a possibilidade de aumento nos níveis desses elementos nos organismos animais.

As pastagens frequentemente têm sua contaminação decorrente da deposição atmosférica, proveniente de fundições, de indústrias diversas e do ambiente urbano (HAMMOND \& ARONSON, 1964). Efluentes contaminados provenientes de diferentes processos industriais ou pequenas atividades urbanas também podem ser responsáveis pela contaminação da água de uso dos animais. A proximidade de convivência e a similaridade em termos fisiológicos com o ser humano, além da coincidência de habitats de vida, fazem com que animais como os bovinos apresentem potencial para serem utilizados como indicadores de contaminação ambiental.

A ingestão acidental, aguda ou crônica, de metais pesados em bovinos pode resultar em inúmeras afecções que, em determinadas ocasiões, podem não ser perceptíveis clinicamente. Por serem animais pouco seletivos, os bovinos podem se contaminar mediante a mastigação de objetos contendo esses elementos químicos ou a partir da ingestão de água ou alimento contaminado. Nesse sentido, o objetivo deste trabalho foi avaliar a contaminação por metais pesados em componentes biológicos de bovinos provenientes de duas regiões ambientalmente contrastantes e em duas épocas de coleta de amostras.

\section{MATERIAL E MÉTODOS}

Bovinos oriundos de duas áreas (industrializada e não-industrializada) do Estado de Minas Gerais (MG), Brasil, foram utilizados neste estudo. Os animais eram fêmeas das raças holandesa ou girolanda e de diferentes idades (dois a quatro anos, média de 2,45 anos). De cada área foram selecionados aleatoriamente 20 animais clinicamente sadios. Amostras de sangue, soro, pelo e leite foram coletadas duas vezes ao ano, sendo uma amostragem realizada no final do inverno e outra no final do verão. As áreas de coleta dos componentes biológicos foram: área $1=$ não-industrializada (controle): formada por bovinos semiestabulados, utilizados para produção de leite e selecionados na zona rural do Município de Viçosa
(MG), em fazendas com distância mínima de $3 \mathrm{~km}$ da área urbana. Os animais não haviam se ausentado da zona rural há, pelo menos, um ano; área $2=$ cidade industrial: formada por animais utilizados para produção de carne ou leite, criados a pasto há pelo menos um ano, oriundos de regiões próximas a siderúrgicas, nos Municípios de Sete Lagoas (MG) e Prudente de Morais (MG).

Após anamnese detalhada, quando foram obtidas informações sobre dados individuais dos bovinos (sexo, idade, raça, peso, utilização principal) e sobre o manejo na propriedade, os animais foram submetidos a um minucioso exame físico, sendo verificado o estado nutricional, o grau de hidratação, a coloração das mucosas, o tempo de enchimento capilar, a temperatura corporal, as frequências cardíaca e respiratória. $\mathrm{O}$ exame físico foi realizado conforme tradicionalmente recomendado (FEITOSA, 2004). As frequências cardíaca e respiratória foram determinadas utilizando-se o estetoscópio. Particularmente em relação ao grau de hidratação, a avaliação foi realizada mediante a verificação do turgor de pele, da umidade da mucosa oral e do tempo de enchimento capilar.

Todos os 40 animais incluídos no projeto apresentaram, no momento das coletas de material, bom estado de hidratação e mucosas normocoradas. O tempo de enchimento capilar esteve dentro dos padrões de referência para a espécie, ou seja, de um a dois segundos (FEITOSA, 2004). O escore corporal médio dos bovinos foi 3 , em uma escala de 1 a 5 , classificada por EDMONDSON et al. (1989), significando uma boa condição corporal.

Em seguida, $10 \mathrm{~mL}$ de amostra de sangue foram coletados de cada animal, por punção da veia jugular externa, em tubos de vidro a vácuo contendo heparina sódica, para análise da concentração de $\mathrm{Pb}$, $\mathrm{Cd}$ e Ni. Para a análise do $\mathrm{Cu}$ e $\mathrm{Zn}$, foram coletados outros $10 \mathrm{~mL}$ de sangue em tubos de vidro sem anticoagulante, que foram, imediatamente após a coleta, submetidos à sedimentação em temperatura ambiente, com posterior centrifugação $(1720 \mathrm{~g}$, durante 10 minutos) para a obtenção do soro, que foi recolhido, identificado e armazenado sob refrigeração até posterior procedimento analítico.

Para determinação do $\mathrm{Pb}$ e Ni, amostras de $0,2 \mathrm{~mL}$ de sangue foram diluídas em $1,8 \mathrm{~mL}$ de solução aquosa contendo $0,1 \%$ de Triton X-100 e $0,2 \%$ de ácido nítrico (KUNO et al., 1999). Para a estimativa dos teores de $\mathrm{Cd}$, amostras de sangue foram previamente submetidas à digestão nitroperclórica $3: 1$, sob temperatura de $150^{\circ} \mathrm{C}$. Já para a quantificação dos teores dos metais pesados $\mathrm{Zn}$ e $\mathrm{Cu}$, as amostras de soro foram diluídas cinco vezes em água Milli-Q (JIAN- 
XIN, 1990). Os elementos Cu e Zn foram determinados por espectrometria de absorção atômica de chama (EAA); Pb e Ni, por EAA com forno de grafite, e o $\mathrm{Cd}$, por espectroscopia de emissão ótica com plasma acoplado indutivamente (ICP-OES). Os resultados foram expressos em $\mu \mathrm{g} \mathrm{mL} \mathrm{L}^{-1}$.

Amostras de $10 \mathrm{~g}$ de pelo da cauda dos bovinos foram coletadas com uma tesoura cirúrgica de aço inoxidável. Apenas as amostras do primeiro centímetro dos pelos mais próximas à pele foram recolhidas, sendo devidamente identificadas e armazenadas em sacos plásticos. Posteriormente, as amostras foram cortadas em fragmentos de aproximadamente $0,3 \mathrm{~cm}$ e lavadas por quatro vezes com solução diluída 1:200 (v/v) de Triton X-100, para a remoção de elementos exógenos. Em seguida, foram enxaguadas por duas vezes com álcool isopropílico e deixadas secar em temperatura ambiente. $\mathrm{Na}$ continuação, foram realizadas lavagens com água MilliQ e duas lavagens com acetona P.A., sendo as amostras deixadas secar em temperatura ambiente. Por fim, as amostras foram secas em chapa aquecedora a $70^{\circ} \mathrm{C}$ (ASANO et al., 2002). A digestão das amostras de pelo foi efetuada de acordo com a técnica descrita por PIMENTA\& VITAL(1994), na qual 0,4g do material foi solubilizado em $10 \mathrm{~mL}$ de ácido nítrico concentrado em chapa aquecedora. Após fervura branda por 30 minutos, foram adicionados $2 \mathrm{~mL}$ de peróxido de hidrogênio $(30 \%)$. Uma vez reduzidos os volumes até próximo à secagem, as soluções foram resfriadas e transferidas para balões volumétricos de $10 \mathrm{~mL}$, e os volumes foram completados com água Milli-Q. Os extratos obtidos foram analisados por ICP-OES, e os resultados foram expressos em $\mu \mathrm{g} \mathrm{g}^{-1}$.

Quanto ao leite, após a limpeza da mama e dos tetos com água deionizada, foram coletados $100 \mathrm{~mL}$ em potes de plásticos pré-lavados em ácido nítrico $10 \%$ (v/v). As amostras foram transportadas sob refrigeração até o laboratório, onde foram congeladas a $-30^{\circ} \mathrm{C}$ até posterior análise. As amostras de leite foram descongeladas em temperatura ambiente e homogeneizadas com agitação manual. Em seguida, foram tomadas alíquotas de $80 \mathrm{~mL}$ e realizadas a evaporação e a secagem do leite em béqueres, em estufa com circulação forçada de ar, com temperatura de $100 \pm 5^{\circ} \mathrm{C}$, por um período de 24 a 36 horas. Na sequência, as amostras sofreram pré-queima em chapa aquecedora a $200^{\circ} \mathrm{C}$ durante cinco a oito horas, sendo levadas posteriormente à mufla para carbonização a $450^{\circ} \mathrm{C}$, por 12 horas. Após resfriamento, foram adicionados $2 \mathrm{~mL}$ de ácido nítrico ( $50 \%)$ às cinzas, sendo posteriormente secas em chapa aquecedora a $70^{\circ} \mathrm{C}$. As cinzas completamente brancas foram dissolvidas em ácido nítrico $1 \mathrm{~mol} \mathrm{~L}^{-1}$ para a obtenção dos extratos. Todo o conteúdo foi transferido para balões volumétricos de $50 \mathrm{~mL}$, que foram completados com água Milli-Q para posterior determinação dos metais pesados em ICPOES. Os resultados foram expressos em $\mathrm{mg} \mathrm{mL}^{-1}$.

No soro, os limites de detecção foram de $0,002 \mathrm{mg} \mathrm{mL}^{-1}$ para $\mathrm{Zn}$ e de $0,004 \mathrm{mg} \mathrm{mL}^{-1}$ para $\mathrm{Cu}$. No sangue, foram de $0,002 \mathrm{mg} \mathrm{mL}^{-1}$ para $\mathrm{Cd}$ e $\mathrm{Ni}$ e de $0,010 \mathrm{mg} \mathrm{mL}^{-1}$ para $\mathrm{Pb}$. No pelo, foram de 0,$001 ; 0,015$; 0,016; 0,021 e 0,033 $\mathrm{mg} \mathrm{g}^{-1}$ para $\mathrm{Cd}, \mathrm{Pb}, \mathrm{Ni}, \mathrm{Cu}$ e $\mathrm{Zn}$, respectivamente. Para o leite, foram de 0,$001 ; 0,002$; 0,012; 0,015 e 0,061 $\mathrm{mg} \mathrm{mL}^{-1}$ para $\mathrm{Cd}, \mathrm{Ni}, \mathrm{Pb}, \mathrm{Cu}$ e Zn, respectivamente.

Os resultados obtidos foram submetidos à análise estatística com programa SAEG 9.0. (UFV, 2007). Inicialmente foi realizada a estatística descritiva dos dados. Os efeitos das áreas (industrializada ou não) e da época do ano de amostragem (inverno ou verão) sobre a concentração dos metais pesados determinados no sangue ( $\mathrm{Pb}, \mathrm{Cd}$ e $\mathrm{Ni}$ ), soro $(\mathrm{Cu}$ e $\mathrm{Zn})$, pelo e leite $(\mathrm{Cu}, \mathrm{Zn}, \mathrm{Pb}, \mathrm{Cd}$ e $\mathrm{Ni}$ ) foram analisados por ANOVA seguida do teste de Tukey $(\mathrm{P}<0,05)$.

\section{RESULTADOS E DISCUSSÃo}

Os resultados referentes aos valores mínimos, máximos e médios da concentração dos metais pesados nas distintas matrizes biológicas são apresentados na tabela 1 . Um bovino (área nãoindustrializada) veio a óbito, por deslocamento do abomaso. Portanto, na coleta do verão, o total de bovinos foi de 39 animais.

Os resultados da ANOVA indicaram efeito significativo da interação dos fatores área e época do ano para alguns dos metais pesados e para algumas matrizes biológicas avaliadas. Quando a interação entre os dois fatores não foi significativa, foram apresentados e discutidos os resultados do efeito isolado de cada um dos dois fatores sobre as concentrações dos metais pesados em cada um dos componentes biológicos avaliados (Tabela 1). No entanto, quando foram verificadas interações significativas entre os fatores, estas foram detalhadas na sequência (Tabela 2).

Nas amostras de soro, observou-se efeito significativo da área de criação e época de amostragem sobre as concentrações médias de $\mathrm{Cu}$. Os animais provenientes da área desprovida de indústrias apresentaram valores inferiores $(\mathrm{P}<0,05)$ aos observados nos bovinos criados próximo às siderúrgicas, e as coletas efetuadas no verão proporcionaram maiores concentrações que no inverno. Efeito da área de criação não foi verificado para o $\mathrm{Zn}$, mas maiores $(\mathrm{P}<0,05)$ concentrações desse metal também foram obtidas no verão. 
Tabela 1 - Concentrações de metais pesados em amostras biológicas de bovinos, em função da área de criação e época do ano de amostragem

\begin{tabular}{|c|c|c|c|c|c|c|}
\hline & & $\begin{array}{l}\text { Área não-industrializada } \\
\qquad\left(\mathrm{N}=39^{*}\right)\end{array}$ & $\begin{array}{l}\text { Área industrializada } \\
\qquad(\mathrm{N}=40)\end{array}$ & Inverno $(\mathrm{N}=40)$ & Verão $\left(\mathrm{N}=39^{\#}\right)$ & $\begin{array}{l}\text { Inter. } \\
\text { AxE }\end{array}$ \\
\hline Soro & $\mathrm{Cu}$ & $\begin{array}{c}0,756^{\mathrm{B}} \\
(0,367-1,427)\end{array}$ & $\begin{array}{c}0,931^{\mathrm{A}} \\
(0,520-3,072)\end{array}$ & $\begin{array}{c}0,701^{\mathrm{b}} \\
(0,420-1,005)\end{array}$ & $\begin{array}{c}0,986^{\mathrm{a}} \\
(0,367-3,072)\end{array}$ & ns \\
\hline$\left(\mu \mathrm{g} \mathrm{mL}^{-1}\right)$ & $\mathrm{Zn}$ & $\begin{array}{c}0,986 \\
(0,345-1,715)\end{array}$ & $\begin{array}{c}0,901 \\
(0,475-2,230)\end{array}$ & $\begin{array}{c}0,771^{\mathrm{b}} \\
(0,475-1,205)\end{array}$ & $\begin{array}{c}1,116^{\mathrm{a}} \\
(0,345-2,230)\end{array}$ & ns \\
\hline \multirow{3}{*}{$\begin{array}{l}\text { Sangue } \\
\left(\mu \mathrm{g} \mathrm{mL}^{-1}\right)\end{array}$} & $\mathrm{Pb}$ & $\begin{array}{c}1,591 \\
(0,020-4,240)\end{array}$ & $\begin{array}{c}1,267 \\
(0,190-4,803)\end{array}$ & $\begin{array}{c}0,827^{\mathrm{b}} \\
(0,020-2,930)\end{array}$ & $\begin{array}{c}2,020^{\mathrm{a}} \\
(1,003-4,803)\end{array}$ & $\mathrm{ns}$ \\
\hline & $\mathrm{Cd}$ & $\begin{array}{c}0,013 \\
(<\mathrm{ld}-0,146)\end{array}$ & $\begin{array}{c}0,017 \\
(<\mathrm{ld}-0,206)\end{array}$ & $\begin{array}{c}0,005^{\mathrm{b}} \\
(<\mathrm{ld}-0,040)\end{array}$ & $\begin{array}{c}0,025^{\mathrm{a}} \\
(<\mathrm{ld}-0,206)\end{array}$ & ns \\
\hline & $\mathrm{Ni}$ & $\begin{array}{c}0,021 \\
(<\mathrm{ld}-0,187)\end{array}$ & $\begin{array}{c}0,028 \\
(<\mathrm{ld}-0,120)\end{array}$ & $\begin{array}{c}0,029 \\
(<\operatorname{ld}-0,120)\end{array}$ & $\begin{array}{c}0,020 \\
(<\mathrm{ld}-0,187)\end{array}$ & * \\
\hline \multirow{5}{*}{$\begin{array}{l}\text { Pelo } \\
\left(\mu \mathrm{g} \mathrm{g}^{-1}\right)\end{array}$} & $\mathrm{Cu}$ & $\begin{array}{c}46,322 \\
(6,97-174,04)\end{array}$ & $\begin{array}{c}8,129 \\
(5,32-28,82)\end{array}$ & $\begin{array}{c}21,216 \\
(5,32-102,76)\end{array}$ & $\begin{array}{c}33,235 \\
(6,19-174,04)\end{array}$ & * \\
\hline & $\mathrm{Zn}$ & $\begin{array}{c}81,762 \\
(31,54-121,11)\end{array}$ & $\begin{array}{c}95,350 \\
(72,31-120,32)\end{array}$ & $\begin{array}{c}89,999 \\
(43,90-110,39)\end{array}$ & $\begin{array}{c}87,113 \\
(31,54-121,11)\end{array}$ & * \\
\hline & $\mathrm{Pb}$ & $\begin{array}{c}0,745 \\
(<\mathrm{ld}-21,018)\end{array}$ & $\begin{array}{c}0,070 \\
(<\mathrm{ld}-0,469)\end{array}$ & $\begin{array}{c}0,677 \\
(<\mathrm{ld}-21,018)\end{array}$ & $\begin{array}{c}0,141 \\
(<\mathrm{ld}-1,469)\end{array}$ & ns \\
\hline & $\mathrm{Cd}$ & $\begin{array}{c}0,025 \\
(<\mathrm{ld}-0,115)\end{array}$ & $\begin{array}{c}0,022 \\
(<\mathrm{ld}-0,058)\end{array}$ & $\begin{array}{c}0,047^{\mathrm{a}} \\
(0,025-0,115)\end{array}$ & $<\mathrm{dd}^{\mathrm{b}}$ & ns \\
\hline & $\mathrm{Ni}$ & $\begin{array}{c}0,143 \\
(<\mathrm{ld}-0,601)\end{array}$ & $\begin{array}{c}0,023 \\
(<\mathrm{ld}-0,200)\end{array}$ & $\begin{array}{c}0,054 \\
(<\mathrm{ld}-0,323)\end{array}$ & $\begin{array}{c}0,112 \\
(<\mathrm{ld}-0,601)\end{array}$ & * \\
\hline \multirow{5}{*}{$\begin{array}{l}\text { Leite } \\
\left(\mu \mathrm{g} \mathrm{mL} \mathrm{mL}^{-1}\right)\end{array}$} & $\mathrm{Cu}$ & $\begin{array}{c}0,063 \\
(<\mathrm{ld}-0,342)\end{array}$ & $\begin{array}{c}0,068 \\
(0,016-0,142)\end{array}$ & $\begin{array}{c}0,060 \\
(<\mathrm{ld}-0,142)\end{array}$ & $\begin{array}{c}0,071 \\
(0,016-0,342)\end{array}$ & $*$ \\
\hline & $\mathrm{Zn}$ & $\begin{array}{c}3,872^{\mathrm{A}} \\
(1,512-8,473)\end{array}$ & $\begin{array}{c}3,152^{\mathrm{B}} \\
(0,803-6,032)\end{array}$ & $\begin{array}{c}3,197^{\mathrm{b}} \\
(1,512-5,373)\end{array}$ & $\begin{array}{c}3,828^{\mathrm{a}} \\
(0,803-8,473)\end{array}$ & ns \\
\hline & $\mathrm{Pb}$ & $<$ ld & $\begin{array}{c}0,003 \\
(<\mathrm{ld}-0,080)\end{array}$ & $\begin{array}{c}0,001 \\
(<\mathrm{ld}-0,016)\end{array}$ & $\begin{array}{c}0,003 \\
(<\mathrm{ld}-0,080)\end{array}$ & ns \\
\hline & $\mathrm{Cd}$ & $<\mathrm{ld}$ & $<\mathrm{ld}$ & $<\mathrm{ld}$ & $<\mathrm{ld}$ & --- \\
\hline & $\mathrm{Ni}$ & $\begin{array}{c}0,002 \\
(<\mathrm{ld}-0,010)\end{array}$ & $\begin{array}{c}0,003 \\
(<\mathrm{ld}-0,017)\end{array}$ & $\begin{array}{c}0,004 \\
(<\mathrm{ld}-0,017)\end{array}$ & $\begin{array}{c}0,002 \\
(<\mathrm{ld}-0,010)\end{array}$ & * \\
\hline
\end{tabular}

Os resultados apresentados referem-se à média (mínimo-máximo); < ld: abaixo do limite de detecção.

\#: óbito de um animal.

No cálculo das médias, os valores $<\mathrm{ld}$ foram considerados como zero.

De acordo com o teste de Tukey $(\mathrm{P}<0,05)$, médias de concentração de metais pesados seguidas de mesma letra maiúscula e médias seguidas de uma mesma letra minúscula, ambas na linha, não diferem entre si para área de criação e época do ano de amostragem, respectivamente. Inter. $\mathrm{AxE}=$ avaliação da interação entre área de criação e época do ano de amostragem (ns: não-significativo; *: $\mathrm{P}<0,05$ ). No caso de interações significativas, não se promoveu a comparação entre médias de áreas de criação e época de amostragem, sendo os desdobramentos avaliados na tabela 2 .

As concentrações médias de $\mathrm{Cu}$ obtidas no soro ficaram discretamente abaixo da faixa de normalidade indicada para a espécie $\left(0,8\right.$ a $\left.1,22 \mu \mathrm{g} \mathrm{mL}^{-1}\right)$ (LUCCI, 1997), nas amostras coletadas na área sem siderúrgicas $\left(0,756 \mu \mathrm{g} \mathrm{mL}^{-1}\right)$ e no inverno $\left(0,701 \mu \mathrm{g} \mathrm{mL}^{-1}\right)$. $\mathrm{Na}$ área industrializada $\left(0,931 \mu \mathrm{g} \mathrm{mL}^{-1}\right)$ e no verão $\left(0,986 \mu \mathrm{g} \mathrm{mL}^{-1}\right)$, os valores médios ficaram dentro da faixa de referência. As concentrações médias de $\mathrm{Zn}$ no soro, independentemente da área e época de coleta, ficaram dentro do intervalo de normalidade indicado para a espécie $\left(0,77\right.$ a $\left.1,15 \mu \mathrm{g} \mathrm{mL}^{-1}\right)$ (RADOSTITS et al., 2002).

Os elementos $\mathrm{Pb}$ e $\mathrm{Cd}$ foram identificados no sangue dos animais, sem que diferenças significativas entre as duas áreas de criação pudessem ser verificadas. Efeito significativo $(\mathrm{P}<0,05)$ foi observado para a época de coleta, com maiores valores sendo obtidos no verão para esses dois metais.

Os teores sanguíneos de toxidez pelo $\mathrm{Pb}$, em bovinos, são inferiores aos valores considerados 
Tabela 2 - Concentrações médias de metais pesados de amostras biológicas de bovinos em decorrência do desdobramento de interações significativas entre áreas de criação e épocas do ano de amostragem.

\begin{tabular}{|c|c|c|c|c|c|}
\hline & & \multicolumn{2}{|c|}{----------Área não-industrializada---------- } & \multicolumn{2}{|c|}{----------Área não-industrializada------- } \\
\hline & & Inverno $(\mathrm{N}=20)$ & Verão (N=19) & Inverno $(\mathrm{N}=20)$ & Verão $(\mathrm{N}=20)$ \\
\hline $\begin{array}{l}\text { Sangue } \\
\left(\mu \mathrm{g} \mathrm{mL}^{-1}\right)\end{array}$ & $\mathrm{Ni}$ & $0,002^{\mathrm{Bb}}$ & $0,040^{\mathrm{Aa}}$ & $0,055^{\mathrm{Aa}}$ & $0,001^{\mathrm{Bb}}$ \\
\hline Pelo & $\mathrm{Cu}$ & $33,683^{\mathrm{Ba}}$ & $58,961^{\text {Аa }}$ & $8,749^{b}$ & $7,508^{b}$ \\
\hline \multirow[t]{2}{*}{$\left(\mu \mathrm{g} \mathrm{g}^{-1}\right)$} & $\mathrm{Zn}$ & $86,926^{\mathrm{A}}$ & $76,599^{\mathrm{Bb}}$ & 93,072 & $97,627^{\mathrm{a}}$ \\
\hline & $\mathrm{Ni}$ & $0,062^{\mathrm{B}}$ & $0,225^{\mathrm{Aa}}$ & 0,045 & $0,001^{\mathrm{b}}$ \\
\hline Leite & $\mathrm{Cu}$ & $0,040^{\mathrm{Bb}}$ & $0,087^{\mathrm{Aa}}$ & $0,081^{\mathrm{a}}$ & $0,055^{\mathrm{b}}$ \\
\hline$\left(\mu \mathrm{g} \mathrm{mL} L^{-1}\right)$ & $\mathrm{Ni}$ & $0,002^{\mathrm{b}}$ & $0,003^{\mathrm{a}}$ & $0,005^{\mathrm{Aa}}$ & $0,001^{\mathrm{Bb}}$ \\
\hline
\end{tabular}

De acordo com o teste de Tukey $(\mathrm{P}<0,05)$, na mesma área, médias de concentração de metais pesados seguidas de mesma letra maiúscula, na linha, não diferem entre si e, na mesma época do ano, médias de concentração de metais pesados seguidas de uma mesma letra minúscula, na linha, não diferem entre si.

para o homem (MARÇAL et al., 2003), sendo estabelecida a concentração de $0,25 \mu \mathrm{g} \mathrm{mL} \mathrm{m}^{-1}$ como limite máximo aceitável e, no ser humano, admite-se um máximo de 0,60 $\mathrm{g} \mathrm{mL}^{-1}$ (GILMAN, 1991). Nesse sentido, as concentrações médias de $\mathrm{Pb}$ verificadas no sangue dos bovinos do presente estudo, independente da área ou da época de amostragem, estão acima do considerado aceitável. Na área industrializada, mesmo os valores mínimos foram mais elevados que os obtidos por KUNO et al. (1999) no sangue de 11 vacas $(0,12 \mu \mathrm{g}$ $\left.\mathrm{mL}^{-1}\right)$, um touro $\left(0,13 \mu \mathrm{g} \mathrm{mL}^{-1}\right)$ e três bezerros $(0,18 \mu \mathrm{g}$ $\mathrm{mL}^{-1}$ ), criados em áreas próximas a um depósito de lixo industrial no Estado de São Paulo. Por outro lado, nenhum dos animais apresentou sinais clínicos de intoxicação pelo metal.

Mesmo que tenha sido verificado efeito significativo da época de amostragem, as concentrações de $\mathrm{Cd}$ no sangue foram baixas e, em sua maioria, menores que o limite de detecção do aparelho. Tal observação é coerente com os dados de PENUMARTHY et al. (1980), os quais verificaram, para várias amostras biológicas de diferentes espécies de animais domésticos, teores de $\mathrm{Cd}$ próximos ou abaixo de $0,005 \mu \mathrm{g} \mathrm{mL}^{-1}$. Ainda assim, com relação à presença de Cd no sangue dos animais estudados, cabe destacar que BUTURE \& MARÇAL (2005) verificaram, em fontes de fósforo utilizadas em formulações minerais de bovinos no Brasil, valores muito acima do teor permitido de Cd $\left(0,5 \mu \mathrm{g} \mathrm{g}^{-1}\right)$ pela legislação (NRC, 1996; AAFCOI, 2001).

Para o Ni determinado no sangue, verificouse interação significativa $(\mathrm{P}<0,05)$ dos fatores área de criação e época do ano de amostragem. Enquanto na área não-industrializada maiores $(\mathrm{P}<0,05)$ concentrações de Ni no sangue foram determinadas no verão (Tabela 2), na área com siderúrgicas, os maiores teores foram verificados no inverno. Por sua vez, no inverno, os teores mais elevados foram diagnosticados na área com indústrias, enquanto no verão as maiores concentrações foram obtidas na área controle. Independentemente da área de criação e da época do ano de amostragem, todos os teores de Ni obtidos no presente estudo foram inferiores a $1,5 \mu \mathrm{g} \mathrm{mL} \mathrm{m}^{-1}$, concentração mencionada como possível de ser encontrada em organismos animais (ÁVILA, 2005).

A análise do cabelo em seres humanos tem sido proposta como meio adicional de se quantificar a absorção crônica de metais pesados. SRIVASTAVA \& GUPTA (1994) referem-se ao cabelo como um importante indicador para se quantificar o grau de exposição a substâncias tóxicas e poluentes, podendo ser efetivamente utilizado no monitoramento da poluição ambiental. A utilização dessa matriz biológica em animais tem sido explorada, tendo em vista sua fácil obtenção, com mínimo de estresse. Entretanto, ainda existe controvérsia com relação à eficiência dessa matriz biológica como indicadora de contaminação. A presença de elementos químicos no cabelo pode se correlacionar com a exposição ambiental ao contaminante, mas também com a idade, a região anatômica de obtenção (CARNEIRO et al., 2002), o estado nutricional e os distúrbios metabólicos (SRIVASTAVA\& GUPTA, 1994).

Os metais pesados $\mathrm{Pb}$ e $\mathrm{Cd}$ foram identificados no pelo dos bovinos estudados sem que diferenças significativas $(P<0,05)$ entre as áreas de criação pudessem ser verificadas (Tabela 1). Não foi detectado $\mathrm{Cd}$ no pelo coletado no verão, o que levou à 
obtenção de diferença significativa com as concentrações obtidas no inverno, época em que o metal foi detectado em todas as amostras analisadas. Por outro lado, a época de amostragem não afetou significativamente as concentrações de $\mathrm{Pb}$ nessa matriz biológica.

Interações significativas entre área de criação e época do ano de amostragem foram verificadas para os teores de $\mathrm{Cu}, \mathrm{Zn}$ e Ni no pelo. Independentemente da época do ano, as concentrações médias de $\mathrm{Cu}$ no pelo foram maiores no grupo de bovinos criados na área não-industrializada (Tabela 2), cujos teores médios obtidos nas duas estações do ano superaram a faixa considerada como referência $(6,6$ a $10,4 \mu \mathrm{g} \mathrm{g}^{-1}$ ) (RADOSTITS et al., 2002). Nos bovinos da área industrializada, não foram verificadas diferenças significativas $(\mathrm{P}<0,05)$ entre as amostragens efetuadas no verão e inverno, enquanto na área desprovida de siderúrgicas maiores teores foram verificados no verão.

Embora o pelo seja considerado por REGIUS-MOCSENYI (1990) como uma das melhores formas de se estimar a concentração corporal de $\mathrm{Zn}$ nos bovinos, os resultados obtidos no presente estudo indicaram haver diferenças significativas $(\mathrm{P}<0,05)$ entre área industrializada e controle apenas no verão. Nessa estação, a área com siderúrgicas apresentou maiores concentrações que a área não-industrializada. Por sua vez, a acumulação diferencial do $\mathrm{Zn}$ nesse compartimento biológico em função da época de amostragem ocorreu apenas na área não-industrializada, onde valores mais elevados do metal foram verificados no inverno $(\mathrm{P}<0,05)$.

Embora aparentemente elevadas, as concentrações máximas de $Z n$ verificadas nas amostras de pelo neste estudo foram menores do que as obtidas por FARMER \& FARMER (2000). Esses autores analisaram a presença de $\mathrm{Zn}$ em diferentes componentes biológicos de bovinos criados em um distrito do Cazaquistão, obtendo teores mais altos no pelo (147,2 $\left.\pm 4,2 \mu \mathrm{g} \mathrm{g}^{-1}\right)$, seguido do músculo $\left(49,3 \pm 8,9 \mu \mathrm{g} \mathrm{g}^{-1}\right)$, do fígado $\left(26,6 \pm 0,9 \mu \mathrm{g} \mathrm{g}^{-1}\right)$, dos rins $\left(19,0 \pm 4,6 \mu \mathrm{g} \mathrm{g}^{-1}\right) \mathrm{e}$ do pulmão $\left(15,7 \pm 5,0 \mu \mathrm{g} \mathrm{g}^{-1}\right)$.

Efeito significativo da área de criação dos animais sobre as concentrações de Ni no pelo somente foi verificado no verão (Tabela 2), estação em que os bovinos da área controle apresentaram maiores teores do metal. No mesmo ambiente de exposição, diferenças significativas entre épocas de amostragem foram verificadas na área não-industrializada, com maiores concentrações sendo determinadas no verão.

Alguns trabalhos sobre a contaminação do leite materno e de produtos lácteos utilizados na alimentação humana estão disponíveis. Entretanto, trabalhos científicos sobre a avaliação do leite de bovinos ainda são escassos. No leite analisado, não foi detectado Cd (Tabela 1), resultado semelhante ao verificado por OKADA et al. (1997), ao analisarem amostras de leite in natura e pasteurizado obtidas no Vale do Paraíba, em São Paulo, após contaminação ambiental por indústria produtora de lingotes de chumbo. Segundo os autores, essa ausência foi decorrente do limite de quantificação do método utilizado, que foi de $0,020 \mu \mathrm{g} \mathrm{mL}^{-1}$. No presente estudo, mesmo com o menor limite de detecção alcançado, o metal não foi detectado.

$\mathrm{O} \mathrm{Pb}$ somente foi detectado nas amostras de leite da área industrializada e diferenças significativas $(\mathrm{P}<0,05)$ não foram verificadas entre épocas de amostragem. Ainda assim, as concentrações médias e máximas de $\mathrm{Pb}$ obtidas na área industrializada foram inferiores ao valor de referência para animais criados em áreas livres de contaminação pelo metal, que é de $0,02 \mu \mathrm{g} \mathrm{mL}^{-1}$ (KUNO et al.,1999). Amostras de leite coletadas pelos autores em animais mantidos em áreas contaminadas alcançaram teores de $\mathrm{Pb}$ de $1,6 \mathrm{a}$ $1,9 \mu \mathrm{g} \mathrm{mL} \mathrm{m}^{-1}$. Diferentemente do mencionado por SWARUP et al. (2005), valores sanguíneos de $\mathrm{Pb}$ acima de $0,20 \mu \mathrm{g} \mathrm{mL}^{-1}$ não acarretaram maior excreção do metal no leite.

As concentrações médias de $\mathrm{Zn}$ nas amostras de leite foram afetadas pela área de criação e época de amostragem. Quanto ao ambiente de exposição, valores significativamente $(\mathrm{P}<0,05)$ mais elevados foram identificados na área desprovida de indústrias. Com relação à época do ano, os maiores teores foram determinados na amostragem efetuada no verão.

Interação significativa $(\mathrm{P}<0,05)$ entre área de criação e época do ano de amostragem foi identificada para o $\mathrm{Cu}$ nas amostras de leite avaliadas (Tabela 2). Considerando os ambientes de exposição, enquanto na área industrializada não foram verificadas diferenças significativas entre as duas estações do ano, na área controle, maiores concentrações foram obtidas nas amostras coletadas no verão. Na mesma época de amostragem foram verificadas diferenças significativas $(\mathrm{P}<0,05)$ entre as concentrações das duas áreas avaliadas. No inverno, os maiores teores foram determinados na área industrial e, no verão, na área controle. As concentrações médias de $\mathrm{Cu}$ nas amostras de leite avaliadas, independentemente da área de criação e da época de amostragem, estiveram dentro da variação considerada como de referência para animais sadios, que é de 0,05 a $0,2 \mu \mathrm{g} \mathrm{mL}^{-1}$ (RADOSTITS et al., 2002). 
As concentrações médias de $\mathrm{Ni}$ nas amostras de leite foram muito baixas, ainda assim interações significativas $(\mathrm{P}<0,05)$ entre área de criação e época de amostragem foram diagnosticadas (Tabela 2), à semelhança do verificado para as matrizes biológicas sangue e pelo. $\mathrm{Na}$ área controle, não foram verificadas diferenças entre as coletas realizadas nas duas estações do ano, enquanto que na área industrializada maiores teores foram obtidos no inverno. Considerando as épocas do ano, no verão, maiores concentrações foram determinadas na área desprovida de siderúrgicas e, no inverno, na área industrializada.

Os resultados obtidos no presente estudo indicam que a presença de siderúrgicas na região avaliada não resultou na elevação das concentrações de metais pesados nas matrizes biológicas testadas, sendo tal efeito limitado ao elemento $\mathrm{Cu}$ nas amostras de soro. Por sua vez, o estudo da época de amostragem indicou efeito da sazonalidade, com tendência de a coleta efetuada no verão proporcionar maiores concentrações de metais pesados em algumas das matrizes biológicas avaliadas. A interação entre o ambiente de exposição e a época de amostragem não pode ser descartada em estudos dessa natureza. Esses resultados podem subsidiar outras pesquisas e outros estudos de monitoramento da qualidade ambiental, nos quais animais são avaliados ou utilizados como bioindicadores da contaminação do meio ambiente.

\section{CONCLUSÕES}

A presença de indústrias em uma determinada região não implica, necessariamente, incrementos nas concentrações de metais pesados em matrizes biológicas bovinas. Pode ocorrer influência da sazonalidade nas concentrações de metais pesados obtidas em matrizes biológicas bovinas.

\section{AGRADECIMENTOS}

Os autores agradecem à Fundação de Amparo à Pesquisa do Estado de Minas Gerais (FAPEMIG), pelo financiamento (CVZ - 244/06) deste estudo e ao Conselho Nacional de Desenvolvimento Científico e Tecnológico (CNPq), pela concessão da bolsa de iniciação científica ao aluno Matheus Werner de Souza Vianna; ao Centro Nacional de Pesquisa de Milho e Sorgo (CNPMS - EMBRAPA) e à Fazenda Experimental Santa Rita (FESR - EPAMIG), pelo apoio durante a execução das coletas de campo e aos revisores, pelas valiosas sugestões.

\section{COMITÊ DE ÉTICA E BISSEGURANÇA}

Este trabalho foi aprovado pela Comissão de Ética do Departamento de Veterinária (processo no 18/2006) da
Universidade Federal de Viçosa, e os estudos foram realizados de acordo com as normas do Código de Ética Profissional do Médico Veterinário e do Colégio Brasileiro de Experimentação Animal (COBEA).

\section{REFERÊNCIAS}

AAFCOI - ASSOCIATION OF AMERICAN FEED CONTROL OFFICIALS INCORPORATED. Official guidelines for contaminant levels permitted in mineral feed ingredients, Indiana, v.9, p.292-293, 2001.

ASANO, R. et al. Concentrations of toxic metals and essential minerals in the mane hair of healthy racing horses and their relation to age. Journal of Veterinary Medical Science, Tokyo, v.64, n.7, p.607-610, 2002. Disponível em: <http:// dx.doi.org/10.1292/jvms.64.607>. Doi: 10.1292/jvms.64.607.

ÁVILA, R. Ortomolecular busca força e vigor para animais atletas. Capturado em out. 2005. Online. Disponível na Internet: http://www.folhaonline/equilibrio.html.

BUTURE, I.O.; MARÇAL, W.S. Teores de chumbo e cádmio em suplementos minerais para bovinos comercializados no estado do Paraná. Archives of Veterinary Science, Curitiba, v.10, n.1, p.51-56, 2005.

CARNEIRO, M.T.W.D. et al. Intervalos de referência para elementos menores e traço em cabelo humano para a população da cidade do Rio de Janeiro - Brasil. Química Nova, São Paulo, v.25, n.1, p.37-45, 2002. Disponível em: $<$ http://dx.doi.org/ 10.1590/S0100-40422002000100008>. Doi: 10.1590/S010040422002000100008 .

DUARTE, R.P.S.; PASQUAL, A. Avaliação do cádmio (Cd), chumbo $(\mathrm{Pb})$, Níquel $(\mathrm{Ni})$ e zinco $(\mathrm{Zn})$ em solos, plantas e cabelos humanos. Energia na Agricultura, Botucatu, v.15, n.1, p.46-58, 2000.

EDMONDSON, A.J. et al. A body condition scoring chart for Holstein dairy cows. Journal of Dairy Science, Savoy, v.72, p.68-78, 1989 .

FARMER, A.A.; FARMER, A.M. Concentrations of cadmium, lead and zinc in livestock feed and organs around a metal production centre in eastern Kazakhstan. Science of the Total Environment, Amsterdam, v.257, n.1, p.53-60, 2000. Disponível em: <http:// dx.doi.org/10.1016/S0048-9697(00)00497-6>. Doi: 10.1016/ S0048-9697(00)00497-6.

FEITOSA, F.L.F. Semiologia veterinária. A arte do diagnóstico. São Paulo: Roca, 2004. 807p.

GILMAN, A. Metais pesados e seus antagonistas. As bases farmacológicas da terapêutica. Rio de Janeiro: Guanabara Koogan, 1991. p.1061-1065.

HAMMOND, P.B.; ARONSON, A.L. Lead poisoning in cattle and horses in the vicinity of a smelter. Annals of New York Academy Science, New York, v.111, p.595-611, 1964. Disponível em: $<$ http://dx.doi.org/10.1111/j.1749-6632.1964.tb53128.x>. Doi: 10.1111/j.1749-6632.1964.tb53128.x

JIAN-XIN, Q.I. Determination of $\mathrm{Cu}, \mathrm{Zn}, \mathrm{Fe}, \mathrm{Ca}, \mathrm{Mg}, \mathrm{Na}$ and $\mathrm{K}$ in serum flame by atomic absorption spectroscopy. Varian Instruments at Work's, Palo Alto, v.93, p.1-2, 1990.

Ciência Rural, v.39, n.6, set, 2009. 
KUNO, R. et al. Lead concentration in blood samples of humans and animal near an industrial waste dump in São Paulo, Brazil. Veterinary and Human Toxicology, Manhattan, v.41, n.4, p.249-250, 1999.

LUCCI, C.S. Nutrição e manejo de bovinos leiteiros. São Paulo: Manole, 1997. 169p.

MARCAL, W.S. et al. Bovinos e eqüinos como bioindicadores da poluição ambiental. Revista Brasileira de Ciência Veterinária, Goiânia, v.10, p.16-20, 2003.

NRC - NATIONAL RESEARCH COUNCIL. Subcommittee on Mineral Toxicity in Animals. Nutrient requirements of beef cattle. Washington: National Academy of Science, 1996. $242 p$

OKADA, I.A. et al. Avaliação dos níveis de chumbo e cádmio em leite em decorrência de contaminação ambiental na região do Vale do Paraíba, Sudeste do Brasil. Revista de Saúde Pública, São Paulo, v.31, n.2, p.140-143, 1997. Disponível em: < http://dx.doi.org/10.1590/S0034-89101997000200006>. Doi: $10.1590 / \mathrm{S} 0034-89101997000200006$

PENUMARTHY, L et al. Lead, cadmium, and mercury tissue residues in healthy swine, cattle, dogs, and horses from the midwestern United States. Archives of Environmental Contamination and Toxicololy, New York, v.9, n.2, p. 193206, 1980. Disponível em: <http://dx.doi.org/10.1007/ BF01055374>. Doi: 10.1007/BF01055374.
PIMENTA, A.S.; VITAL, B.R. Contaminação de pintores profissionais por metais pesados provenientes de tintas e vernizes. Química Nova, São Paulo, v.17, p.277-280, 1994.

RADOSTITS, O.M. et al. Clínica veterinária. Um tratado de doenças dos bovinos, ovinos, suínos, caprinos e eqüinos. 9.ed. Rio de Janeiro: Guanabara Koogan, 2002. 1737p.

REGIUS-MOCSENYI, A. Zn, Mn, $\mathrm{Cu}, \mathrm{Mo}, \mathrm{Ni}$ and $\mathrm{Cd}$ supplementation of cattle, sheep and horses. 1. $\mathrm{Zn}$ supplementation. Allattenyesztes es Takarmanyozas, Budapest, v.39, n.3, p.255-270, 1990.

SRIVASTAVA, A.K.; GUPTA, B.N. The role of human hairs in health and disease with special reference to environmental exposures. Veterinary and Human Toxicology, Manhattan, v.36, n.6, p.556-560, 1994

SWARUP, D. et al. Blood lead levels in lactating cows reared around polluted localities; transfer of lead into milk. Science of Total Environment, Shannon, v.347, p.106-110, 2005. Disponível em: $<$ http://dx.doi.org/doi:10.1016/j.scitotenv.2004.12.079>. Doi: 10.1016/j.scitotenv.2004.12.079.

UFV - Universidade Federal de Viçosa. SAEG. Sistema para análises estatísticas, versão 9.1. Capturado em 12 dez. 2007. Online. Disponível na Internet: http://www.ufv.br/saeg/. 